\title{
Managing Knowledge and Scholarly Assets in Academic Libraries
}

Part of the Advances in Library and Information Science Book Series

Premier Reference Source

Bhojaraju Gunjal (National Institute of Technology Rourkela, India)

Managing Knowledge

and Scholarly Assets in

Academic Libraries

\section{Description:}

Knowledge management strategies play an important role across numerous industries. These processes and strategies can be adopted into higher education sectors for use in managing scholarly assets.

Managing Knowledge and Scholarly Assets in Academic Libraries is an essential reference source for the latest research on approaches for adopting and implementing various facets of knowledge management in academia. Features expansive coverage on a range of topics and perspectives, such as knowledge mapping, social media applications, and linked data.

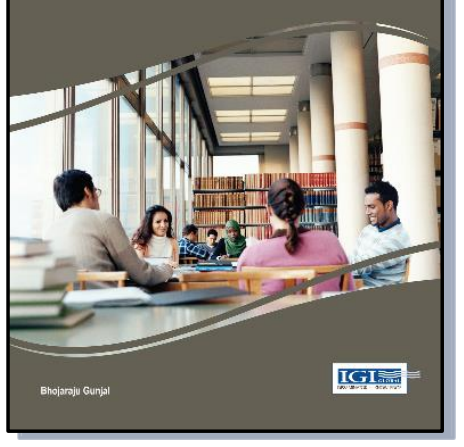

\section{Readers:}

This publication is ideally designed for librarians, students, managers, and scholars seeking current research on the innovative measures of knowledge management in libraries.

\section{Topics Covered:}

- $\quad$ After Action Review (AAR)

- Institutional Repositories

- Knowledge Mapping

- $\quad$ Linked Data
- $\quad$ Online Blogging

- Semantic Web

- Social Media

- Web 2.0 Tools
Hardcover + Free E-Book:

$\$ 180.00$
E-Book Only:

$\$ 180.00$ 
Table of Contents

Theme 1:

Knowledge Management: An overview

Chapter 1

Knowledge Management: An Overview

Chapter 2

Mastering Knowledge Management in Academic Libraries

Theme 2:

Knowledge Management Strategy

Chapter 3

Knowledge sharing cultural dimensions from team and organization perspective

Chapter 4

The Embedded Librarian: Delivering demand driven knowledge services through a Service Level Agreement

\section{Theme 3:}

Applications of KM in libraries

Chapter 5

Knowledge Management as an Academic Discipline: An

Assessment

Chapter 6

The Transformative Role of Institutional Repositories in Academic Knowledge Management

Chapter 7

Use of Institutional Repository for Information Dissemination and Knowledge Management

Chapter 8

Utilising ICTs for resource sharing initiatives in academic institutions in Zimbabwe: Towards a new trajectory
Theme 4:

Applications of Tools, Technologies and Methods

Chapter 9

Semantic Web, Ontology and Linked Data

Chapter 10

Web 2.0 Tools and Application: Knowledge Management and Sharing in Libraries

Chapter 11

Knowledge System and Spiral of Scientific Method By Dr. S.R. Ranganathan

Chapter 12

Thesaurus Construction and Knowledge Management in Information Centers in the Scope of Knowledge Mapping in Public Institutions: The Experience and Initial Results of a Knowledge Mapping Project (BIHAP) in Turkey

Theme 5:

Challenges and Issues

Chapter 13

Managing Knowledge and Scholarly Assets in Academic Libraries: Issues and Challenges

Theme 6:

Case Studies of KM implementations

Chapter 14

Knowledge Management Practices at IIMs: A Study

Chapter 15

Knowledge Management Capability in Higher Education: The Case of Lecturers at Mzuzu University, Malawi

Bhojaraju Gunjal lives in Rourkela and serves as Head, Central Library (Deputy Librarian) at National Institute of Technology Rourkela, Odisha, India. Prior to this, he served as Deputy Librarian at Thapar University, Patiala, Punjab and Knowledge Management (KM) Consultant at TATA Consultancy Services (TCS), Bangalore. He has over 15 years of professional experience in Library Management, Knowledge management, Enterprise Content Management and Project Management in both academic and IT Sectors using ECM tools such as SharePoint, Documentum and InQuira. Has strong understanding of business processes, integration strategies and techno-functional expertise in different industrial areas. You may also refer my detailed profile at http://bhojaraju.weebly.com. 